\title{
Urinary Tract Infections During Pregnancy
}

\author{
Anick Bérard ${ }^{1,2}$, Fabiano Santos ${ }^{1,2}$, Ema Ferreira ${ }^{1,2}$ and Sylvie Perreault ${ }^{1}$ \\ ${ }^{1}$ Faculty of Pharmacy, University of Montreal, Montreal, Quebec \\ ${ }^{2}$ Research Center, CHU Sainte-Justine, Montreal, Quebec, \\ Canada
}

\section{Introduction}

Urinary tract infections (UTIs) are one of the most common medical complications of pregnancy (Mittal \& Wing, 2005). It is estimated that one in three women of childbearing age will have a UTI (Duarte et al., 2008). Because of the normal physiologic changes induced by gestation, pregnant women are especially susceptible to these infections.

UTIs are characterized by the presence of infectious agents in the genito-urinary tract that cannot be explained by contamination. These agents have the potential to invade the tissues of the urinary tract and adjacent structures. The microbiological profile is well known and pathogens such as Escherichia coli have been present in the vast majority of cases (Sheffield \& Cunningham, 2005). The infection may be limited to the growth of bacteria in the urine (which frequently don't produce symptoms) or it can result in several syndromes associated with an inflammatory response to the bacterial invasion. Actually, the term UTI represent a wide variety of conditions, including asymptomatic forms of UTIs, urethritis, cystitis, acute pyelonephritis and pyelonephritis with bacteremia or sepsis (Joseph DiPiro et al., 2011).

There are several classification methods for these infections. In this chapter, we will refer to UTIs as follows:

- Asymptomatic bacteriuria is defined as the presence of more than $10^{8}$ colonies/L of urine, without the symptoms of an acute UTI (Schnarr \& Smaill, 2008);

- lower tract infection and upper tract infections, according to the anatomical site of contamination (Joseph DiPiro et al., 2011) ;

- Lower UTIs: The anatomical site of the infection can be the bladder (cystitis) and/or the urethra (urethritis) (Joseph DiPiro et al., 2011);

- Upper UTIs: The kidneys are the anatomical site of the infection (pyelonephritis associated with inflammation of the renal parenchyma, calices and pelvis) (Wagenlehner et al., 2009);

- Uncomplicated UTIs: infections occurring in individuals who lack structural or functional abnormalities of the urinary tract that interfere with the normal flow of urine or voiding mechanism (Joseph DiPiro et al., 2011);

- Complicated urinary tract infections: infections occurring in individuals with predisposing lesions of the urinary tract that interferes with the normal flow of urine and urinary tract defences. Common causes of predisposing lesions are birth defects, 
kidney stones, catheters, or obstruction (Masson et al., 2009). An UTI during pregnancy is considered complicated.

During gestation, untreated UTIs can lead to several pregnancy complications, such as low birth weight infants, premature delivery, and occasionally, stillbirth. Prompt and efficacious treatment of symptomatic UTIs is warranted in pregnant women. Nevertheless, there is still some controversy regarding the screening and treatment of asymptomatic forms during gestation (Lin and Brown 2010; Lumbiganon et al., 2010; Schmiemann et al., 2010).

Given the prevalence and the potential impacts of UTIs on the health of the mother and her child, the objective of this chapter is to cover the most important clinical aspects of the epidemiology, etiology, physiopathology, pregnancy outcomes, and the treatment risks and benefits associated with UTIs during pregnancy.

\section{Epidemiology}

It is estimated that 2 to $10 \%$ of pregnant woman suffer from any form of UTIs (Lee et al., 2008). These infections complicate up to $20 \%$ of pregnancies and are responsible for the majority of antepartum admissions to the maternal-fetal medicine units (Sheffield \& Cunningham, 2005).

The prevalence of asymptomatic forms of UTIs has remained constant across countries, and most of the recent observational studies report similar rates, ranging from 2 to $10 \%$ - similar to that of nonpregnant women (Duarte et al., 2008; Bahadi et al., 2010). Acute cystitis is prevalent in 1 to $4 \%$ of pregnant women (Wagenlehner et al., 2009).

Despite the relatively low prevalence of pyelonephritis during pregnancy (0.5 to $2 \%)$, it is estimated that $20 \%$ to $40 \%$ of pregnant women with asymptomatic bacteriuria will develop this condition later in gestation (Jolley \& Wing, 2010). A study showed that if UTI is left untreated, $30 \%$ of mothers will develop acute pyelonephritis compared with $1.8 \%$ of nonbacteriuric controls ${ }^{2}$. Many studies have reported that pyelonephritis is more common during the second half of pregnancy, with an incidence peak during the last two trimesters of pregnancy (Gilstrap et al., 1981; Hill et al., 2005; Sharma \& Thapa, 2007). Acute pyelonephritis may lead to adverse outcomes for the baby and the mother, such as premature delivery, low birth weight infants, preeclampsia, hypertension, renal failure and fetal death (Hill et al., 2005).

The prevalence of UTI in pregnancy is closely related to socioeconomic factors (Turck et al., 1962). Predictors of UTIs' asymptomatic forms include: welfare status, increasing maternal age, multiparity, risky sexual behavior, history of childhood UTIs and history of recurrent UTIs. It has been reported that indigent women have a five-fold greater incidence of bacteriuria than non-indigent populations (Turck et al., 1962; Golan et al., 1989). The prevalence is also markedly increased if women present certain pre-existing medical conditions, such as diabetes mellitus, sickle cell disease, immuno-deficiency states, urinary tract anatomic anomalies, spinal cord injuries and psychiatric illnesses (Ovalle et al., 1989). Nevertheless, there is some controversy on the effects of these host factors as predictors of UTIs (Fatima \& Ishrat, 2006). UTI before pregnancy is a predictor for the diagnosis of asymptomatic bacteriuria at the first prenatal visit (Tugrul et al., 2005). Risk factors for developing cystitis and pyelonephritis in pregnancy include those stated before, as well as a history of Clamidia trachomatis infection, illicit drug use, and having less than 12 years of education (Verani et al., 2010). 
It was suggested that UTIs screening and testing algorithms should be designed, incorporating identified risk factors in order to lower overall costs and to improve maternal and infant outcomes (Chng \& Hall, 1982; Pastore et al., 1999). To date, no such algorithm has been prospectively evaluated (Schnarr \& Smaill, 2008).

\section{Etiology and physiopathology}

\subsection{Microbiology}

In normal physiological circumstances, the genito-urinary tract is sterile. The microorganisms causing UTIs usually originate from the gastro-intestinal flora of the host. For example, during pregnancy bacteriuria can occur when bacteria from a fecal source gains access to the bladder by ascending the relatively short female urethra (Patterson \& Andriole, 1997). Patogens causing bacteriuria are similar in both pregnant and nonpregnant women (Schnarr \& Smaill, 2008). Although virtually every organism can be associated with UTIs, certain organisms predominate as a result of specific virulence and host susceptibility factors (Joseph DiPiro et al., 2011).

The most common agent implicated in uncomplicated UTIs is Escherichia coli, which accounts for $85 \%$ of non-hospital setting infections (Harris \& Gilstrap, 1981; Millar \& Cox, 1997; Sharma \& Thapa, 2007). Other microorganisms such as Staphylococcus saprophyticus (5\% to $15 \%$ of cases) (Mittal \& Wing, 2005), Gardnerella vaginalis, Chlamydia trachomatis, Klebsiella pneumoniae, Proteus spp., Pseudomonas aeruginosa, Enterococcus spp. (5\% to 10\%), Ureaplasma urealyticum and lactobacilli have also been associated with UTIs. Although the clinical significance of these organisms on UTIs during pregnancy was not yet appreciated, a few small studies have reported improved outcomes following therapy against these agents (Gilbert et al., 1986; Cohen et al., 1990). The consensus is that during gestation, most UTIs are caused by a single organism. Nevertheless, organisms isolated from pregnant women with complicated UTIs are more varied and generally are more resistant to treatment than those found in uncomplicated infections. Anaerobic and other fastidious microorganisms have been identified in the urine of a large percentage of pregnant women, but the role played by these organisms on adverse perinatal outcomes is unknown (Gilbert et al., 1986). There is evidence that some bacterial strains can replicate inside the cells, explaining the difficulties in treating some cases, given that these strains are protected from the action of anti-infective drugs (Rosen et al., 2007). At present, there is no evidence showing advantages in routinely examining the urine for these uncommon organisms.

\subsection{Physiopathology}

For many years, pregnancy was seen as a period that naturally predisposes to all forms of UTIs. This was explained by the fact that genito-urinary anatomical and physiological changes induced by gestation predispose women with asymptomatic bacteriuria to develop symptomatic UTIs, leading to the impression that the number of UTIs was higher during this period of life (Nowicki, 2002). Nowadays, it is known that gestation itself is not the only responsible for the increased risk of UTIs. Throughout pregnancy, UTIs often persist, owing to re-infection (Foxman \& Brown, 2003).

During gestation the urethra is colonized by bacteria originated from the gastro-intestinal and perineal flora (Naveen \& Mathai, 2005). Other factors that can predispose urethral colonization include the use of some methods of contraception before pregnancy, such as spermicides and diaphragms (Fihn, 2003; Foxman \& Brown, 2003). Although there is 
evidence that bladder infections follow colonization of the urethra, the mode of ascent of the microorganisms is not completely elucidated. After reaching the bladder, the organisms quickly multiply and can ascend the ureters to the kidneys. This sequence of events is more likely to occur if reflux of urine into the ureters and kidneys is present.

Bacterial colonization is facilitated as early as the renal pelvis and ureters begin to dilate (eighth week of gestation), and the bladder is displaced superiorly and anteriorly inside the intra-abdominal cavity (Jeyabalan \& Lain, 2007). Mechanical compression caused by the enlarging uterus is the principle cause of this dilatation, but smooth muscle relaxation induced by progesterone may also play a role. The main consequences of these changes are the decrease in peristalsis of the ureters, followed by an increase in bladder capacity and urinary stasis. It is known that the decreased renal capacity to concentrate urine during pregnancy reduces the antibacterial activity of this fluid, leading it to excrete smaller amounts of potassium and higher amounts of glucose, amino acids and hormone degradation products. These biochemical alterations turn the urine into an alkaline solution, thus providing a suitable environment for bacterial growth (Dafnis \& Sabatini, 1992). Additionally, the increase in the estrogen induced by gestation, contribute to the adhesion of certain E. coli strains to the type 1 uroepithelial cells (Roos et al., 2006).

Host protective factors such as the low glucose concentration of the urine, stability of the vaginal lactobacilli population, the influence of estrogens, the activity of Tamm-Horsfall protein, the presence of urinary mucus or slime (called glycosaminoglycan) and the immunologic defense mechanisms, makes the normal urinary tract generally resistant to invasion and efficient in rapidly eliminating microorganisms that reach the bladder (Parsons et al., 1978; Joseph DiPiro et al., 2011).

Specific subsets of E. coli clones identified with $\mathrm{O}, \mathrm{K}$ and $\mathrm{H}$ antigens were shown to have increased propensity to cause UTIs (Kaper, 2005; Naveen \& Mathai, 2005). An important virulence factor of bacteria is their ability to adhere to urinary epithelial cells, resulting in colonization of the urinary tract, bladder infections, and pyelonephritis. Uropathogenic $E$. coli have such virulence factors, known as fimbrias or pilli. These are adherence proteins (adhesins) expressed on the bacterial wall surface that promote binding to the epithelium of the vagina and urethra, thus increasing E. coli ability to cause UTIs (Sandberg et al., 1988). Adhesins include type 1, S and P fimbriae, and adhesins like Dr (Kaper, 2005). This property was recognized decades ago, and it is what differentiates uropathogenic E. coli from the gastro-intestinal commensal forms (Eden et al., 1976).

The type 1 fimbriae are prevalent and are probably involved in colonization of lower urinary tract (Naveen \& Mathai, 2005). The role of P fimbriae in upper UTI is well documented (Wullt et al., 2002). These are present in 20\% of faecal E. coli, $60 \%$ of cystitis causing, and $80 \%$ of $E$. coli isolated in pyelonehritis (Kaper, 2005). Attachment of P fimbriae to urinary tract epithelium is also associated with increased host inflammatory response (Wullt et al., 2002). Other factors that increase E. coli virulence include production of haemolysin, serum resistance and release of aerobactin (Wullt et al., 2002). Haemolysin provides $E$. coli a possible selective advantage by releasing iron from lysed erythrocytes and thus, enhancing pathogenicity by destroying phagocytic and epithelial cells (Naveen \& Mathai, 2005).

Animal models and human data suggest that E. coli can remain hidden in large bacterial reservoirs within the host and can be reactivated to cause infection in the future, when there is some local decrease in the normal activity of the host defense factors (Mulvey et al., 2001; 
Epp et al., 2010). Midstream urine samples from women with acute uncomplicated cystitis also showed evidence of intracellular bacterial communities of uropathogenic $E$. coli (Rosen et al., 2007). These communities are relatively protected from host immune response mechanisms and antibiotic therapy. They may be reactivated, causing recurrent UTI (Rosen et al., 2007).

There is some controversy concerning the role played by the physiological changes occuring during pregnancy which could be the main factor predisposing pregnant women to UTIs (Nowicki et al., 2011). Some authors claim that the biological complexity and molecular epidemiology of UTI suggest that mechanical obstruction can only partially explain the risk of developing gestational UTI (Nowicki, 2002). It is argued that if gestation alone predisposes to UTIs, urine stasis and obstruction should favour infection in the presence of avirulent random gram-negative and gram-positive species. Instead, $90 \%$ of gestational UTIs are associated with uropathogenic virulent $E$. coli strains, which (in contrast) are seldom isolated in the non-pregnant patients with urinary tract obstructive problems. To date, this issue remains controversial.

\section{Clinical presentation and diagnosis}

\subsection{Clinical presentation}

Given that UTIs correspond to the growth and multiplication of bacteria within the urinary tract, the resulting lesions can result in different degrees of severity. These infections can be grouped into four different clinical entities, according to the anatomical location of injury, maintaining relations between them (see Introduction section).

In 1962, Kass brought attention and concern to asymptomatic bacteriuria, noting that this form of infection was one of the most important predisposing factors for pyelonephritis in pregnant women (Kass, 1962). Since then, there was a step forward to recognize the importance of early diagnosis of this form of infection in early pregnancy, avoiding the complications of pyelonephritis (MacLean, 2001; Smaill, 2007). Asymptomatic bacteriuria is characterized by bacterial colonization of the urine, and if it shows no clinical symptoms, microbiological laboratory tests are needed to support its diagnosis (MacLean, 2001). Asymptomatic bacteriuria is defined by two consecutive clean-catch urine cultures with more than $10^{8}$ colonies/L of urine, with a single type of bacteria (Shand et al., 1970). It is believed that the vast majority of pregnant women that developing UTIs' symptomatic forms during gestation have asymptomatic bacteriuria at the time of conception. It was observed that $30 \%$ of women with asymptomatic bacteriuria developed symptomatic UTI during gestation (Gratacos et al., 1994).

Urethritis is characterized by urethral colonization resulting in dysuria and polyuria. Approximately $50 \%$ of pregnant women suffering from this complication do not have significant asymptomatic bacteriuria, and in $30 \%$ of them, urine cultures are negative. From a practical standpoint, only $20 \%$ of symptomatic patients have urine culture with more than $10^{8}$ colonies/L of urine. Another important detail is that some etiological agents involved in urethritis are germs commonly found in the vaginal cavity and that cause genital infections some cannot be detected in routine urine cultures, such as Chlamydia trachomatis and Mycoplasma hominis (Nicolle, 2006). However, the potential invasiveness of these bacteria in the urinary tract is low.

Cystitis is the infection of the bladder, occurring in about 1 to $1.5 \%$ of pregnancies. Common clinical manifestations are dysuria, polyuria, suprapubic discomfort, and in some cases, 
hematuria (Le et al., 2004). Although dysuria and polyuria may suggest UTIs, these symptoms may concomitantly be present in pregnant women with other conditions, such as bacterial vaginosis (Duarte et al., 2008). In addition, hemorrhagic cystitis during pregnancy can be confounded with bleeding issued from a process that could be bacterial, viral, fungal, immune (allergic) and radiotherapy. Cystitis is associated with preterm delivery and should be treated as soon as detected (Fakhoury et al., 1994).

Pyelonephritis is the most severe form of UTI in pregnant women and may affect up to $2 \%$ of this population. Its occurrence is directly associated with the prevalence of asymptomatic bacteriuria among pregnant women (Gilstrap et al., 1981; Nowicki, 2002). This condition can occur with or without symptoms of cystitis. Overall, pyelonephritis is associated with worse maternal and prenatal prognosis (Schieve et al., 1994). Clinical signs and symptoms of pyelonephritis include flank pain (unilateral or bilateral) or abdominal pain, fever, anorexia, nausea and vomiting often associated with variable degrees of dehydration, chills, headache, and tachypinea. Respiratory failure and sepsis can be present in severe forms. Fever is elevated in the acute forms (Rosen et al., 2007). When considering the clinical diagnosis of UTIs during pregnancy, it is useful to remember that some symptoms of infection are difficult to characterize because they can be normally present during gestation, such as polyuria. In addition, asymptomatic bacteriuria does not present any clinical manifestation. However, patient history and risk factors can identify women at higher risk of UTI (Pastore et al., 1999; Nowicki, 2002; Fatima \& Ishrat, 2006; Roos et al., 2006).

\subsection{Diagnosis}

Given the increased incidence of symptomatic UTI during pregnancy and its association with maternal and perinatal complications, screening of asymptomatic bacteriuria during pregnancy is requested with two urine samples obtained at different times. Testing a single sample may provide false-positive result in up to $40 \%$ of cases (MacLean, 2001). This measure can allow early start treatment and reduces the rate of progression to symptomatic infection and it's potentially harmfull consequences (Gratacos et al., 1994; Smaill, 2007).

Current laboratory tests for the diagnosis of UTI are based on the color changes of chemical reactants according to urine composition (dipstick analysis). Two of these are important for their rapidity and low costs: the test of nitrite and the test of leukocyte esterasis. The nitrite test is based on the ability of certain bacteria to reduce the urinary nitrate to nitrite. This test has $50 \%$ sensitivity and specificity of $97 \%$, and can result in false positives when used on urine contaminated by normal vaginal bacteria or highly concentrated urine, given that the test follows colorimetric principles. The leukocyte esterase test has low sensitivity and specificity $(25 \%)$ and can also result in false positives. Both tests have low sensitivity and therefore not suitable as screening tests for diagnosis, unless they are used in combination with other tests (McNair et al., 2000).

Microscopic urinalysis is the examination of one drop of centrifuged and uncoloured fresh urine, with dry objective (400 times magnification). The observation of any bacteria per field correlates with a urine culture of at least $10^{8}$ colonies/L of urine. Despite being a low cost test, its low sensitivity limits it to be indicated in the screening of asymptomatic bacteriuria (McNair et al., 2000). Current evidence seems to indicate that the microscopic analysis of a Gram-colored urine sample is a more suitable and rapid test for UTI screening. It consists in the microscopic observation of the urine bacteria Gram stain, improving the accuracy of microscopic urinalysis (Duarte et al., 2008). 
Several alternative laboratory methods can be used for the diagnosis of UTIs with varying sensitivities and specificities. Therefore, the association of these tests can be necessary to confirm the positive results of a urinalysis. Moreover, for their meaningfull interpretation, it become imperative to use correct techniques for collecting the urine sample (aseptic perineal urine midstream, immediate transportation and refrigeration at $4{ }^{\circ} \mathrm{C}$ for, no later than 24 hours) (Nicolle, 2006).

Among the abnormalities likely to be detected in a urinalysis, we can find pyuria, hematuria, proteinuria and cylinders in the urinary sediment. These findings can indicate UTI, but actually they are just signs of inflammation and may also be present in other conditions. It should be remembered that a normal urinalysis result does not exclude the diagnosis of UTI, hence, not being ideal for screening of asymptomatic bacteriuria during pregnancy. However, in symptomatic patients, the result of this test is accepted for the initiation of therapy until the results of urine microbiologic culture are known (Nicolle, 2006; Duarte et al., 2008).

The urine microbiologic culture is considered the gold standard for laboratory diagnosis of UTI. It is the most accurate method to identify and quantify bacteria in the urine with high sensibility (MacLean, 2001). Its drawbacks are the relatively higher costs, the long time needed to achieve the number of bacterial colonies necessary for a sensitive result and the need for professionals and laboratories qualified for its elaboration (Rosen et al., 2007). The correct interpretation of a urine culture is crucial for therapeutic success. In asymptomatic cases, the finding of more than $10^{8}$ colonies/L of urine suggests infection. Values between $10^{7}$ and $10^{8}$ correspond to infection in $50 \%$ of cases. If the urine is collected by bladder catheterization, the finding of values above $10^{6}$ indicates infection; if the urine is issued by suprapubic aspiration, infection is diagnosed with any number of bacteria. In symptomatic cases, urine cultures are considered positive with up to $10^{5}$ bacteria $/ \mathrm{mL}$ of urine (Nicolle, 2006).

Other important complementary tests include total and differential blood cells count, and dosage of metabolites such as urea and creatinine. These tests help to identify the severity of the infection, reflected in the hematologic and renal function parameters. However, they are not essential for the monitoring of patients with uncomplicated UTIs. Ultrasound of kidneys and urinary tract can be considered an important complementary examination. In addition of being rapid, inexpensive, easily accessible and totally safe for both mother and fetus, they can help to identify predisposing factors for adverse pregnancy outcomes, such as urinary calculus and pathological dilatation of the renal collecting system (Duarte et al., 2008).

\section{UTIs and pregnancy outcomes}

Several studies have associated UTIs during gestation with the risk of adverse perinatal and maternal outcomes. Some other studies failed to prove such associations (Gilstrap et al., 1981; Reddy \& Campbell, 1985; Chen et al., 2010). Inconsistencies in the results of these studies could be due to selection bias, low statistical power and inadequate control for potential confounders. As stated before, the general consensus is that UTIs can lead to complications, such as low-birth-weight infants, premature delivery, and, occasionally, stillbirth (Lee et al., 2008). 


\subsection{UTIs and maternal outcomes}

The maternal complications of UTI are a result of the tissue damage caused by bacterial endotoxins, especially in pyelonephritis (Neal, 2008). The most dramatic maternal complication associated with UTIs is bacteremia and septic shock, induced by resistant pyelonephritis (Mittal \& Wing, 2005). Endotoxin-mediated damage includes diminished peripheral vascular resistance and changes in cardiovascular output. With the release of E. coli endotoxin active component of (lipid A) into the maternal circulation, a cascade response of pro-inflammatory cytokines, histamine, and bradykinins is precipitated, which may lead to the more serious complications (septic shock, disseminated intravascular coagulation, respiratory insufficiency, and adult respiratory distress syndrome (Galajdova, 2010)). This syndrome is defined as a disease of acute onset with bilateral infiltrates on chest radiograph and hypoxemia without evidence of pulmonary hypertension (Graves, 2002), and complicates $1 \%$ to $8 \%$ of cases of pyelonephritis in pregnancy (Wing, 1998). Women who have septic shock require admission to intensive care, immediate fluid resuscitation, and antimicrobial therapy. Although patients generally respond well to oxygen therapy, worsening dyspnea, tachypnea, and hypoxemia may signify progress to adult respiratory distress syndrome (Graves, 2002). Respiratory failure and pulmonary edema can result from an increased permeability of the alveolar-capillary membrane. This condition can be worsened by the use of hyperhydration and tocolytics, often administered for inhibition of preterm labor (Duarte et al., 2008). Although bacteremia is detected in $15-20 \%$ of women with severe pyelonephritis, few of them develop clinical manifestations of septic shock.

Other maternal complications that have been associated with UTIs during pregnancy are hypertension and preeclampsia (Conde-Agudelo et al., 2008; Rustveld et al., 2008), anemia (Fede, 1983), chorioamnionitis and endometritis (Schieve et al., 1994; Delzell \& Lefevre, 2000). The causal nature of these associations is questionable, because it is not always clear whether an episode of UTI preceded the particular outcome of interest, especially in what concerns maternal hypertension and anemia (Schieve et al., 1994).

The relationship between UTIs during pregnancy and preeclampsia is consistent throughout studies performed over the last years, and is present in diverse settings worldwide (CondeAgudelo et al., 2008). Several mechanisms have been proposed to explain how maternal infection might be involved in the etiology of preeclampsia or its manifestations. These include direct effects of the infectious agents on the arterial walls, including endothelial injury or dysfunction, acute atherosis, and local inflammation that might cause relative uteroplacental ischemia (von Dadelszen \& Magee, 2002). Furthermore, some authors have hypothesized that the infection might be involved in both the initiation of the pre-eclampsia process (by increasing the risk of acute uteroplacental atherosis) and/or its potentiation (by amplifying the maternal systemic inflammatory response) (Herrera et al., 2001). Nevertheless, these hypotheses are issued from animal data and some other authors argue that the association between UTIs and preeclampsia may not be real and may be due to confounding. For example, abnormal changes associated with chronic pyelonephritis and papillary necrosis has been observed in almost half of women with bacteriuria during pregnancy (Whalley et al., 1965). These underlying diseases and the impairment of renal function they cause could, thus, account for the higher risk of preeclampsia among women with bacteriuria (Conde-Agudelo et al., 2008). More data is needed to determine whether the relationship between maternal UTIs and preeclampsia is causal. 
Local complications, such as urinary obstruction, perinephric abscess and cellulitis are rare and when present, are associated with lithiasis or treatment-resistant microorganisms (Le et al., 2004; Neal, 2008).

\subsection{UTIs and perinatal outcomes}

The association between perinatal outcomes and UTIs has been studied for many years (Mittal \& Wing 2005; Duarte et al., 2008). From a global health perspective, UTI is one of the most important and potentially preventable causes of early preterm birth (Simmons et al., 2010). Intrauterine infections are thought to be responsible for up to $50 \%$ of extreme preterm births of less than 28 weeks of gestation, where both neonatal mortality and morbidity are high (Simmons et al., 2010). Observational studies show an association between maternal UTIs and preterm birth and low birth weight (Gravett et al., 2010). Most of these studies are conducted in lower and middle income countries. Therefore, there is a great deal of heterogeneity between studies regarding the association between these infections and the risk of preterm birth (Beck et al., 2010). Among other recognized perinatal complications of UTI, we highlight premature rupture of membranes, intrauterine growth restriction, cerebral palsy/mental retardation and perinatal death (Romero et al., 1989; Polivka et al., 1997; McDermott et al., 2000; Duarte et al., 2008). Some cases of periventricular leukomalacia and fetal septicemia have been recently reported as a result of transplacental transfer of cytokines originated from maternal UTIs (Spinillo et al., 1998; Oda et al., 2008). Pregnancies complicated by UTIs are also associated with increased fetal mortality (McDermott et al., 2001).

It was estimated that $27 \%$ of preterm deliveries are associated with pre-existing UTIs (Turiani, 2009). In the same study, the investigators found that women with pyelonephritis had prevalence for low birth weight infants of $15 \%$ (defined as birth weight less than 2500 grams). Same findings were reported in a large cohort study conducted in the USA. In this study, UTIs were also associated with the risk of small-for-gestational-age newborns (Schieve et al., 1994). Evidence issued from microbiological analysis of the genito-urinary tract of women with premature labor or preterm rupture of membranes, show that UTI is the most important risk factor for perinatal morbidity and fetal death (Turiani, 2009). Data from 52 cases of neonatal sepsis showed that UTIs were present in $63 \%$ of cases (Ananthakrishnan \& Gunasekaran, 2009). All the aforementioned adverse pregnancy outcomes are important predictors of neonatal mortality.

Data on the treatment of UTI and its effect on pregnancy outcomes corroborate the observation that these infections, if left untreated, are associated with low birth weight. In one study, the risk of preterm delivery in women who had asymptomatic UTI was two times greater than in unaffected women. With adequate treatment, the risk of low birth weight infants was 44\% lower when compared to the untreated group (Gilstrap et al., 1981; Romero et al., 1989). These findings were confirmed in a recent Cochrane review which demonstrated the decreased incidence of pyelonephritis and low birth weight infants when asymptomatic UTI was treated (Smaill \& Vazquez, 2007).

The increased incidence of preterm labor and delivery associated with UTIs can be explained by the inflammatory response induced by citokines and prostaglandins mediators. Another way in which preterm labor can be triggered is through the colonization of amniotic fluid by uropathogens originated from UTIs. These bacteria produce phospholipases A and C, that act as precursors of pro-contractile prostaglandins E2 and F2a, 
consequently triggering preterm labor (Duarte et al., 2008; Bhutta et al., 2010). There are several mechanisms suggested to explain the high rates of premature rupture of membranes in pregnant women with UTI. One of them is that UTIs induces the release of metalloproteinases by macrophages, via cytokines which degrade the membranes, predisposing them to rupture, in a similar way as do collagenasis and phospholipasis issued from bacteria (Sayres, 2010) (Wax et al., 2010).

There has also been a hypothesis suggesting that UTI during pregnancy is associated with child developmental delay and mental retardation (Broman, 1987). One study has found a $30 \%$ increase in the risk for cognitive delay in children whose mothers had UTI during pregnancy, when compared to children whose mothers were not infected (McDermott et al., 2001). Furthermore, when comparing untreated women with treated women, the risk of having infants with cognitive delay was $22 \%$ higher. These results support the association between UTI in pregnancy and cognitive delay and emphasize the importance of the rapid diagnosis and treatment. However, the multifactorial nature of these outcomes makes the determination of etiology difficult, and no firm consensus has been reached on this subject (Mittal \& Wing 2005).

Given the burden of UTI during pregnancy, with regards to adverse maternal and pregnancy outcomes, these infections must be adequately diagnosed and efficient treatment must be initiated. Screening and treatment of assympomatic UTI during pregnancy is recommended by the U.S. Preventive Services Task Force (USPSTF, 2010). Given the evidence indicating that detection and treatment of asymptomatic bacteriuria with antibiotics significantly reduces the incidence of maternal UTIs and low birth weight, the USPSTF concludes that during pregnancy, there is high certainty that the net benefit of screening for asymptomatic bacteriuria is substantial. Nevertheless, in men and nonpregnant women, there is moderate certainty that the harms of screening for asymptomatic bacteriuria outweighs the benefits (Lin \& Brown, 2010). The USPSTF discloses that the urine culture is the standard criterion for detecting asymptomatic bacteriuria. Nevertheless, as previously discussed, it is recognized that this test is expensive for routine screening in populations with a low prevalence of the condition. However, no currently available tests have a high enough sensitivity and negative predictive value (Lin \& Fajardo, 2008). The screening tests used commonly in primary care (dipstick analysis and direct microscopy) have poor positive and negative predictive value for detecting bacteriuria in asymptomatic persons (Bandyopadhyay et al., 2005, 2010). Pregnant women with asymptomatic bacteriuria should receive antibiotic therapy directed at the cultured organism and followup monitoring. The screening intervals must be between 12 to 16 weeks' gestation or at the first pre-natal visit, if later, although there is no consensus in the literature as to the optimal timing and screening frequency for asymptomatic bacteriuria (McIsaac et al., 2005; Tugrul et al., 2005; Schnarr \& Smaill, 2008).

\section{Treatment of UTIs during pregnancy}

Data from observational studies showed that the prevalence of anti-infective use during pregnancy is $24.5 \%$ (Santos et al., 2010a). Once the clinical diagnosis of UTI is established, treatment is mandatory even when no confirmation of the UTI etiological agent by the microbiologic culture test is available. As a consequence, the initial antibiotic therapy has the drawback of being empirical, and a variety of different antimicrobial agents can be used for the treatment of bacteriuria (Gilstrap \& Ramin, 2001). Therefore, a periodic 
assessment of the sensitivity pattern of etiological agents against anti-infective drugs commonly used to treat UTIs must be done. This measure becomes extremely important given the growing number of bacterial resistant to the antibiotics that are deemed safe during pregnancy (Duarte et al., 2008). It is important to remember that therapy must be safe for both mother and fetus. Nearly all anti-infective drugs are able to cross the placenta, and therefore agents that may be harmful to the developing fetus should be avoided. Antibiotics that have been associated with teratogenic effects are quinolones, trimethropime/sulfamethoxazole, chloramphenicol, and tetracycline (Macejko \& Schaeffer, 2007).

Quinolones has been associated to the development of arthropathy when given directly to immature animals and is not usually recommended for routine use during pregnancy. This adverse effect has not been described in humans (Gilstrap \& Ramin, 2001; Macejko \& Schaeffer, 2007; Lee et al., 2008). Tetracycline has been associated with yellow-brown discoloration of the deciduous teeth, when used after the 16th week of gestation, and gentamicin could potentially cause eighth nerve damage in the fetus (Dashe \& Gilstrap, 1997; Schnarr \& Smaill, 2008).

Given that pregnant women are not enrolled in randomised clinical trials assessing safety, there is no clear consensus on the choice of antibiotics and the duration of treatment during gestation. As a consequence, practice is more likely guided by national patterns of prescription and local bacterial resistance profiles (Schnarr \& Smaill, 2008). Antibiotics commonly used for the treatment of UTIs during pregnancy have not been found to be associated with an increased risk of birth defects. Beta lactams antibiotics, such as penicillins and cephalosporins, are deemed safe during pregnancy and are commonly prescribed for the treatment of UTIs during the gestational period (Lee et al., 2008; Schnarr \& Smaill, 2008; Guinto et al., 2010, Santos et al., 2010a). Despite the fact that no drug of this class has any apparent teratogenic properties, beta-lactams are sometimes associated with allergic and anaphylactic reactions. In addition, high bacterial resistance rates limit the use of some agents, such as amoxicillin or ampicillin (Dashe \& Gilstrap, 1997; Guinto et al., 2010).

Safety of nitrofurantoin in pregnancy has already been demonstrated (Ben David et al., 1995). Nitrofurantoin only achieves therapeutic levels in the urine, so it cannot be used to treat pyelonephritis. This drug is not active against Proteus spp (Christensen, 2000; Sahm et al., 2001). There is a theoretical risk of nitrofurantoin-induced hemolytic anemia in the fetusor newborn, particularly in those with glucose-6-phosphate dehydrogenase (G6PD) deficiency (Smaill \& Vazquez, 2007; Guinto et al., 2010).

Trimethoprim is a folic acid antagonist and its use during the first trimester has been associated with neural tube and cardiovascular defects in the newborn (Milo et al., 2005). Sulfonamides could theoretically displace bilirubin from albumin-binding sites and could cause severe jaundice leading to kernicterus. Practical evidence of this risk, however, is sparse (Smaill, 2000). Furtheremore, a recent study showed an association between exposure to sulphonamides during the last two trimesters of pregnancy and the risk of small for gestational age newborns (Santos et al., 2010b).

Follow-up of women with asymptomatic bacteriuria is important because approximately one third of them will experience a recurrent infection during pregnancy. For women with frequent recurrent episodes of bacteriuria or symptomatic UTIs, prophylactic continuous antibiotic treatment should be considered. However, the protracted use of antibiotics, especially ampicillin and cephalosporins, may interfere with the normal gastrointestinal flora. Prolonged use of these antibiotics may be associated with chronic vulvovaginitis secondary to overgrowth of Candida albicans (Gilstrap \& Ramin 2001). 
Table 1 summarizes most common therapeutic regimens currently proposed for the treatment of UTIs during pregnancy, according to the type of UTIs (Bruel et al., 2000; Milo et al., 2005; Mittal \& Wing, 2005; Cimolai \& Cimolai, 2007; Rosen et al., 2007; Duarte et al., 2008; Guinto et al., 2010).

\begin{tabular}{|c|c|c|c|}
\hline $\begin{array}{l}\text { Urinary tract } \\
\text { infection }\end{array}$ & Treatment regimen & Treatment options & Comments \\
\hline $\begin{array}{c}\text { Assymptomatic } \\
\text { bacteriuria }\end{array}$ & $\begin{array}{c}\text { Current standard } \\
\text { of practice is to } \\
\text { treat pregnant } \\
\text { patients who have } \\
\text { asymptomatic } \\
\text { bacteriuria with at } \\
\text { least } 3 \text { to } 7 \text { days of } \\
\text { an oral anti- } \\
\text { infective agent } \\
\text { (Rubin et al., 1992; } \\
\text { Connolly \& Thorp, } \\
\text { 1999; Christensen, } \\
\text { 2000; Gilstrap \& } \\
\text { Ramin, 2001; } \\
\text { Ovalle \& } \\
\text { Levancini, 2001). }\end{array}$ & \begin{tabular}{|} 
Cephalexin $250-500 \mathrm{mg}$, \\
po, qid \\
Nitrofurantoin $100 \mathrm{mg}$, \\
po, qid or \\
Nitrofurantoin \\
(monohydrate $/ \mathrm{macro}-$ \\
crystals) $100 \mathrm{mg}$, po, \\
bid, 7 days \\
Amoxicillin $500 \mathrm{mg}$, po, \\
tid \\
Norfloxacin $400 \mathrm{mg}$, po, \\
bid \\
Cefuroxim $250 \mathrm{mg}$, po, \\
tid \\
SXT (320/1600 mg) po, \\
once a day (avoid use \\
during first trimester)
\end{tabular} & $\begin{array}{l}\text { Single-dose and three days regimens } \\
\text { have been used, but showed lack of } \\
\text { efficacy. Some authors do not } \\
\text { recommend during gestation (Rubin et } \\
\text { al., 1992; Smaill \& Vazquez, 2007). } \\
\text { SXT was associated with a theoretical } \\
\text { increased risk of neural tube defects } \\
\text { and it may lead to neonatal kernicterus } \\
\text { (Schnarr \& Smaill, 2008). } \\
\text { Nitrofurantoin was associated with } \\
\text { theoretical risk of fetal hemolytic } \\
\text { anemia when mother has G6PD } \\
\text { deficiency (Smaill \& Vazquez, 2007). } \\
\text { Given the increased rates of bacterial } \\
\text { resistance to ampicillin and } \\
\text { cephalexin, one must verify hospital } \\
\text { susceptibilities before prescribing b- } \\
\text { lactam monotherapy (Mittal \& Wing, } \\
\text { 2005; Joseph DiPiro et al., 2011). }\end{array}$ \\
\hline $\begin{array}{l}\text { Urethritis and } \\
\text { cystitis }\end{array}$ & $\begin{array}{l}\text { Given that the } \\
\text { pathogens } \\
\text { associated with } \\
\text { urethritis and } \\
\text { cystitis are the } \\
\text { same as those } \\
\text { causing } \\
\text { asymptomatic } \\
\text { bacteriuria, the } \\
\text { treatment of } \\
\text { cystitis in } \\
\text { pregnancy is the } \\
\text { same as the } \\
\text { treatment for } \\
\text { asymptomatic } \\
\text { bacteriuria, longer } \\
\text { courses of therapy } \\
\text { are usually } \\
\text { recommended (7- } \\
10 \text { days) (Gilstrap } \\
\text { \& Ramin, 2001). }\end{array}$ & $\begin{array}{c}\text { Cefuroxim } 250 \mathrm{mg} \text {, po, } \\
\text { tid } \\
\text { Nitrofurantoin } 100 \mathrm{mg}, \\
\text { po, qid or } \\
\text { Nitrofurantoin } \\
\text { (monohydrate } / \text { macro- } \\
\text { crystals) } 100 \mathrm{mg} \text {, po, bid } \\
\text { Amoxicillin } 500 \mathrm{mg} \text {, po, } \\
\text { tid } \\
\text { SXT (320/1600 mg) po, } \\
\text { once a day (avoid use } \\
\text { during first trimester) }\end{array}$ & $\begin{array}{c}\text { These agents are FDA class B category } \\
\text { (Mittal \& Wing, 2005). }\end{array}$ \\
\hline
\end{tabular}




\begin{tabular}{|c|c|c|c|}
\hline $\begin{array}{l}\text { Urinary tract } \\
\text { infection }\end{array}$ & Treatment regimen & Treatment options & Comments \\
\hline Pyelonephritis & $\begin{array}{c}\text { Initial treatment } \\
\text { must be } \\
\text { parentheral } \\
\text { (Vazquez \& Villar, } \\
\text { 2003; Duarte et al., } \\
\text { 2008). First-line } \\
\text { therapy often } \\
\text { includes a first- } \\
\text { generation } \\
\text { cephalosporin. In } \\
\text { an inpatient } \\
\text { setting, parenteral } \\
\text { antimicrobial } \\
\text { therapy usually is } \\
\text { continued until the } \\
\text { patient is afebrile } \\
\text { for } 48 \text { hours } \\
\text { (Wing, 1998). The } \\
\text { patient is switched } \\
\text { to oral } \\
\text { antimicrobial } \\
\text { therapy for } 2 \\
\text { weeks (total). }\end{array}$ & $\begin{array}{c}\text { Ampicillin } 2 \text { grams, IV, } \\
\text { q6h (+) Gentamicin 1.5- } \\
\text { 1.7/mg/kg, IV, q6 h } \\
\text { Gentamicin 1.5- } \\
\text { 1.7/mg/kg, IV, q8h } \\
\text { Ampicillin-sulbactam } 3 \\
\text { grams, IV, q6 h } \\
\text { Ceftriaxone } 1 \text { gram, } \\
\text { IV/IM, q24 h } \\
\text { Cefuroxime 0.75-1.5 } \\
\text { grams, IV, q8 h } \\
\text { Cefazolin } 2 \text { grams, IV, } \\
\text { q6-8 h } \\
\text { Mezlocillin } 3 \text { grams, IV, } \\
\text { q6 h } \\
\text { Piperacillin } 4 \text { grams IV } \\
\text { q8 h } \\
\text { Ticarcillin/clavulanate } \\
3.1 \text { grams, IV, q6h }\end{array}$ & $\begin{array}{l}\text { Ampicillin monotherapy showed high } \\
\text { incidence of resistant bacteria, and } \\
\text { therefore, usually is used in } \\
\text { conjunction with gentamicin (Dunlow } \\
\text { \& Duff, 1990). } \\
\text { To avoid exacerbation of the renal } \\
\text { insufficiency that commonly } \\
\text { accompanies pyelonephritis, drug } \\
\text { serum levels should be monitored } \\
\text { when using aminoglycosides, such as } \\
\text { gentamicin (Wing, 1998). }\end{array}$ \\
\hline
\end{tabular}

Table 1. Most common therapeutic regimens currently proposed for the treatment of UTIs during pregnancy (Abbreviations: po: by mouth; q: every; bid: twice a day; tid: three times a day; qid: four times a day; SXT: Trimethoprim/Sulfamethoxazole; IM: intramuscularly; IV: intravenously).

\section{Conclusion}

Urinary tract infection is a prevalent complication of pregnancy that can worsen maternal and perinatal prognosis. Untreated asymptomatic forms can progress to pyelonephritis, which is associated with preterm delivery, low birth weight infants and stillbirth. In addition to the increased incidence of UTIs during gestation, health care professionals must be aware that the choice of available anti-infective drugs are restricted, given the risk of certain of them for the fetus, and the potential for bacterial resistance. Most of the drugs used for the treatment of UTIs during pregnancy are not associated with an increased risk of birth defects. Early diagnosis followed by immediate and adequate therapy is essential during gestation, avoiding compromising maternal and neonatal health.

\section{Acknowledgment}

Dr. Anick Bérard is the recipient of a career award from the Fonds de la Recherche en Santé du Québec (FRSQ) and is on the endowment Research Chair of the Famille Louis-Boivin on 
Medications, Pregnancy and Lactation at the Faculty of Pharmacy of the University of Montreal. Fabiano Santos is the recipient of the Sainte-Justine Hospital Foundation and the Foundation of Stars scholarship and of the Robert Dugal scholarship (Health Research Foundation and Faculty of Pharmacy of the University of Montreal). The authors have no conflict of interest to declare.

\section{References}

A U.S. Preventive Services Task Force. (2010) Screening for asymptomatic bacteriuria in adults: reaffirmation recommendation statement. Am Fam Physician, 81, 505.

Ananthakrishnan, S. \& Gunasekaran, D. (2009) Etiology and risk factors for early onset neonatal sepsis. Indian J Med Microbiol, 27, 279.

Bahadi, A., El Kabbaj, D., Elfazazi, H., Abbi, R., Hafidi, M.R., Hassani, M.M., Moussaoui, R., Elouennass, M., Dehayni, M. \& Oualim, Z. (2010) Urinary tract infection in pregnancy. Saudi J Kidney Dis Transpl, 21, 342-344.

Bandyopadhyay, S., Thakur, J.S., Ray, P. \& Kumar, R. (2005) High prevalence of bacteriuria in pregnancy and its screening methods in north India. J Indian Med Assoc, 103, 259-262, 266.

Beck, S., Wojdyla, D., Say, L., Betran, A.P., Merialdi, M., Requejo, J.H., Rubens, C., Menon, R. \& Van Look, P.F. (2010) The worldwide incidence of preterm birth: a systematic review of maternal mortality and morbidity. Bull World Health Organ, 88, 31-38.

Ben David, S., Einarson, T., Ben David, Y., Nulman, I., Pastuszak, A. \& Koren, G. (1995) The safety of nitrofurantoin during the first trimester of pregnancy: meta-analysis. Fundam Clin Pharmacol, 9, 503-507.

Bhutta, Z.A., Lassi, Z.S., Blanc, A. \& Donnay, F. (2010) Linkages among reproductive health, maternal health, and perinatal outcomes. Semin Perinatol, 34, 434-445.

Broman, S.H. (1987) Prenatal risk factors for mental retardation in young children. Public Health Rep, 102, 55-57.

Bruel, H., Guillemant, V., Saladin-Thiron, C., Chabrolle, J.P., Lahary, A. \& Poinsot, J. (2000) [Hemolytic anemia in a newborn after maternal treatment with nitrofurantoin at the end of pregnancy]. Arch Pediatr, 7, 745-747.

Chen, Y.K., Chen, S.F., Li, H.C. \& Lin, H.C. (2010) No increased risk of adverse pregnancy outcomes in women with urinary tract infections: a nationwide population-based study. Acta Obstet Gynecol Scand, 89, 882-888.

Chng, P.K. \& Hall, M.H. (1982) Antenatal prediction of urinary tract infection in pregnancy. Br J Obstet Gynaecol, 89, 8-11.

Christensen, B. (2000) Which antibiotics are appropriate for treating bacteriuria in pregnancy? J Antimicrob Chemother, 46 Suppl 1, 29-34; discussion 63-25.

Cimolai, N. \& Cimolai, T. (2007) Nitrofurantoin and pregnancy. CMAJ, 176, 1860-1861.

Cohen, I., Veille, J.C. \& Calkins, B.M. (1990) Improved pregnancy outcome following successful treatment of chlamydial infection. JAMA, 263, 3160-3163.

Conde-Agudelo, A., Villar, J. \& Lindheimer, M. (2008) Maternal infection and risk of preeclampsia: systematic review and metaanalysis. Am J Obstet Gynecol, 198, 7-22.

Connolly, A. \& Thorp, J.M., Jr. (1999) Urinary tract infections in pregnancy. Urol Clin North Am, 26, 779-787. 
Dafnis, E. \& Sabatini, S. (1992) The effect of pregnancy on renal function: physiology and pathophysiology. Am J Med Sci, 303, 184-205.

Dashe, J.S. \& Gilstrap, L.C., 3rd (1997) Antibiotic use in pregnancy. Obstet Gynecol Clin North Am, 24, 617-629.

Delzell, J.E., Jr. \& Lefevre, M.L. (2000) Urinary tract infections during pregnancy. Am Fam Physician, 61, 713-721.

Duarte, G., Marcolin, A.C., Quintana, S.M. \& Cavalli, R.C. (2008) [Urinary tract infection in pregnancy]. Rev Bras Ginecol Obstet, 30, 93-100.

Dunlow, S. \& Duff, P. (1990) Prevalence of antibiotic-resistant uropathogens in obstetric patients with acute pyelonephritis. Obstet Gynecol, 76, 241-244.

Eden, C.S., Hanson, L.A., Jodal, U., Lindberg, U. \& Akerlund, A.S. (1976) Variable adherence to normal human urinary-tract epithelial cells of Escherichia coli strains associated with various forms of urinary-tract infection. Lancet, 1, 490-492.

Epp, A., Larochelle, A., Lovatsis, D., Walter, J.E., Easton, W., Farrell, S.A., Girouard, L., Gupta, C., Harvey, M.A., Robert, M., Ross, S., Schachter, J., Schulz, J.A., Wilkie, D., Ehman, W., Domb, S., Gagnon, A., Hughes, O., Konkin, J., Lynch, J., Marshall, C., Society of, O. \& Gynaecologists of, C. (2010) Recurrent urinary tract infection. J Obstet Gynaecol Can, 32, 1082-1101.

Fakhoury, G.F., Daikoku, N.H. \& Parikh, A.R. (1994) Management of severe hemorrhagic cystitis in pregnancy. A report of two cases. J Reprod Med, 39, 485-488.

Fatima, N. \& Ishrat, S. (2006) Frequency and risk factors of asymptomatic bacteriuria during pregnancy. J Coll Physicians Surg Pak, 16, 273-275.

Fede, T. (1983) Urinary tract infection and anemia in pregnancy. Clin Exp Obstet Gynecol, 10, 140-141.

Fihn, S.D. (2003) Clinical practice. Acute uncomplicated urinary tract infection in women. N Engl J Med, 349, 259-266.

Foxman, B. \& Brown, P. (2003) Epidemiology of urinary tract infections: transmission and risk factors, incidence, and costs. Infect Dis Clin North Am, 17, 227-241.

Galajdova, L. (2010) Pulmonary dysfunction in acute antepartum pyelonephritis and other pregnancy infections. J Obstet Gynaecol, 30, 654-658.

Gilbert, G.L., Garland, S.M., Fairley, K.F. \& McDowall, D.M. (1986) Bacteriuria due to ureaplasmas and other fastidious organisms during pregnancy: prevalence and significance. Pediatr Infect Dis, 5, S239-243.

Gilstrap, L.C., 3rd, Cunningham, F.G. \& Whalley, P.J. (1981a) Acute pyelonephritis in pregnancy: an anterospective study. Obstet Gynecol, 57, 409-413.

Gilstrap, L.C., 3rd \& Ramin, S.M. (2001) Urinary tract infections during pregnancy. Obstet Gynecol Clin North Am, 28, 581-591.

Gilstrap, L.C., Leveno, K.J., Cunningham, F.G., Whalley, P.J. \& Roark, M.L. (1981b) Renal infection and pregnancy outcome. Am J Obstet Gynecol, 141, 709-716.

Golan, A., Wexler, S., Amit, A., Gordon, D. \& David, M.P. (1989) Asymptomatic bacteriuria in normal and high-risk pregnancy. Eur J Obstet Gynecol Reprod Biol, 33, 101-108.

Gratacos, E., Torres, P.J., Vila, J., Alonso, P.L. \& Cararach, V. (1994) Screening and treatment of asymptomatic bacteriuria in pregnancy prevent pyelonephritis. J Infect Dis, 169, 1390-1392. 
Graves, C.R. (2002) Acute pulmonary complications during pregnancy. Clin Obstet Gynecol, 45, 369-376.

Gravett, M.G., Rubens, C.E. \& Nunes, T.M. (2010) Global report on preterm birth and stillbirth (2 of 7): discovery science. BMC Pregnancy Childbirth, 10 Suppl 1, S2.

Guinto, V.T., De Guia, B., Festin, M.R. \& Dowswell, T. (2010) Different antibiotic regimens for treating asymptomatic bacteriuria in pregnancy. Cochrane Database Syst Rev, CD007855.

Harris, R.E. \& Gilstrap, L.C., 3rd (1981) Cystitis during pregnancy: a distinct clinical entity. Obstet Gynecol, 57, 578-580.

Herrera, J.A., Chaudhuri, G. \& Lopez-Jaramillo, P. (2001) Is infection a major risk factor for preeclampsia? Med Hypotheses, 57, 393-397.

Hill, J.B., Sheffield, J.S., McIntire, D.D. \& Wendel, G.D., Jr. (2005) Acute pyelonephritis in pregnancy. Obstet Gynecol, 105, 18-23.

Jeyabalan, A. \& Lain, K.Y. (2007) Anatomic and functional changes of the upper urinary tract during pregnancy. Urol Clin North Am, 34, 1-6.

Jolley, J.A. \& Wing, D.A. (2010) Pyelonephritis in pregnancy: an update on treatment options for optimal outcomes. Drugs, 70, 1643-1655.

Joseph DiPiro, R.T., Gary Yee, Gary Matzke, Barbara Wells, L. Michael Posey (2011) Pharmacotherapy: A Pathophysiologic Approach. McGraw-Hill Medical.

Kaper, J.B. (2005) Pathogenic Escherichia coli. Int J Med Microbiol, 295, 355-356.

Kass, E.H. (1962) Pyelonephritis and bacteriuria. A major problem in preventive medicine. Ann Intern Med, 56, 46-53.

Le, J., Briggs, G.G., McKeown, A. \& Bustillo, G. (2004) Urinary tract infections during pregnancy. Ann Pharmacother, 38, 1692-1701.

Lee, M., Bozzo, P., Einarson, A. \& Koren, G. (2008) Urinary tract infections in pregnancy. Can Fam Physician, 54, 853-854.

Lin, K. \& Fajardo, K. (2008) Screening for asymptomatic bacteriuria in adults: evidence for the U.S. Preventive Services Task Force reaffirmation recommendation statement. Ann Intern Med, 149, W20-24.

Lin, K.W. \& Brown, T. (2010) Screening for asymptomatic bacteriuria in adults. Am Fam Physician, 81, 508.

Lumbiganon, P., Laopaiboon, M. \& Thinkhamrop, J. (2010) Screening and treating asymptomatic bacteriuria in pregnancy. Curr Opin Obstet Gynecol, 22, 95-99.

Macejko, A.M. \& Schaeffer, A.J. (2007) Asymptomatic bacteriuria and symptomatic urinary tract infections during pregnancy. Urol Clin North Am, 34, 35-42.

MacLean, A.B. (2001) Urinary tract infection in pregnancy. Int J Antimicrob Agents, 17, 273276; discussion 276-277.

Masson, P., Matheson, S., Webster, A.C. \& Craig, J.C. (2009) Meta-analyses in prevention and treatment of urinary tract infections. Infect Dis Clin North Am, 23, 355-385;

McDermott, S., Callaghan, W., Szwejbka, L., Mann, H. \& Daguise, V. (2000) Urinary tract infections during pregnancy and mental retardation and developmental delay. Obstet Gynecol, 96, 113-119. 
McDermott, S., Daguise, V., Mann, H., Szwejbka, L. \& Callaghan, W. (2001) Perinatal risk for mortality and mental retardation associated with maternal urinary-tract infections. J Fam Pract, 50, 433-437.

McIsaac, W., Carroll, J.C., Biringer, A., Bernstein, P., Lyons, E., Low, D.E. \& Permaul, J.A. (2005) Screening for asymptomatic bacteriuria in pregnancy. J Obstet Gynaecol Can, 27, 20-24.

McNair, R.D., MacDonald, S.R., Dooley, S.L. \& Peterson, L.R. (2000) Evaluation of the centrifuged and Gram-stained smear, urinalysis, and reagent strip testing to detect asymptomatic bacteriuria in obstetric patients. Am J Obstet Gynecol, 182, 10761079.

Millar, L.K. \& Cox, S.M. (1997) Urinary tract infections complicating pregnancy. Infect Dis Clin North Am, 11, 13-26.

Milo, G., Katchman, E.A., Paul, M., Christiaens, T., Baerheim, A. \& Leibovici, L. (2005) Duration of antibacterial treatment for uncomplicated urinary tract infection in women. Cochrane Database Syst Rev, CD004682.

Mittal, P. \& Wing, D.A. (2005) Urinary tract infections in pregnancy. Clin Perinatol, 32, 749764.

Mulvey, M.A., Schilling, J.D. \& Hultgren, S.J. (2001) Establishment of a persistent Escherichia coli reservoir during the acute phase of a bladder infection. Infect Immun, 69, 4572-4579.

Naveen, R. \& Mathai, E. (2005) Some virulence characteristics of uropathogenic Escherichia coli in different patient groups. Indian J Med Res, 122, 143-147.

Neal, D.E., Jr. (2008) Complicated urinary tract infections. Urol Clin North Am, 35, 13-22; v.

Nicolle, L.E. (2006) Asymptomatic bacteriuria: review and discussion of the IDSA guidelines. Int J Antimicrob Agents, 28 Suppl 1, S42-48.

Nowicki, B. (2002) Urinary Tract Infection in Pregnant Women: Old Dogmas and Current Concepts Regarding Pathogenesis. Curr Infect Dis Rep, 4, 529-535.

Nowicki, B., Sledzinska, A., Samet, A. \& Nowicki, S. (2011) Pathogenesis of gestational urinary tract infection: urinary obstruction versus immune adaptation and microbial virulence. BJOG, 118, 109-112.

Oda, N., Takeuchi, K., Tanaka, A. \& Maruo, T. (2008) Obstetric risk factors associated with the development of periventricular leukomalacia in preterm infants born to mothers complicated by placenta previa. Fetal Diagn Ther, 24, 345-348.

Ovalle, A. \& Levancini, M. (2001) Urinary tract infections in pregnancy. Curr Opin Urol, 11, 55-59.

Ovalle, A., Silva, O., Herrera, R., Gonzalez, E. \& Marin, J. (1989) [Pre-existing diseases as risk factors and prognosis of genito-urinary infection in pregnancy]. Rev Chil Obstet Ginecol, 54, 341-347.

Parsons, C.L., Shrom, S.H., Hanno, P.M. \& Mulholland, S.G. (1978) Bladder surface mucin. Examination of possible mechanisms for its antibacterial effect. Invest Urol, 16, 196200.

Pastore, L.M., Savitz, D.A. \& Thorp, J.M., Jr. (1999) Predictors of urinary tract infection at the first prenatal visit. Epidemiology, 10, 282-287. 
Patterson, T.F. \& Andriole, V.T. (1997) Detection, significance, and therapy of bacteriuria in pregnancy. Update in the managed health care era. Infect Dis Clin North Am, 11, 593-608.

Polivka, B.J., Nickel, J.T. \& Wilkins, J.R., 3rd (1997) Urinary tract infection during pregnancy: a risk factor for cerebral palsy? J Obstet Gynecol Neonatal Nurs, 26, 405-413.

Reddy, J. \& Campbell, A. (1985) Bacteriuria in pregnancy. Aust N Z J Obstet Gynaecol, 25, 176-178.

Romero, R., Oyarzun, E., Mazor, M., Sirtori, M., Hobbins, J.C. \& Bracken, M. (1989) Metaanalysis of the relationship between asymptomatic bacteriuria and preterm delivery/low birth weight. Obstet Gynecol, 73, 576-582.

Roos, V., Nielsen, E.M. \& Klemm, P. (2006) Asymptomatic bacteriuria Escherichia coli strains: adhesins, growth and competition. FEMS Microbiol Lett, 262, 22-30.

Rosen, D.A., Hooton, T.M., Stamm, W.E., Humphrey, P.A. \& Hultgren, S.J. (2007) Detection of intracellular bacterial communities in human urinary tract infection. PLoS Med, 4, e329.

Rubin, R.H., Shapiro, E.D., Andriole, V.T., Davis, R.J. \& Stamm, W.E. (1992) Evaluation of new anti-infective drugs for the treatment of urinary tract infection. Infectious Diseases Society of America and the Food and Drug Administration. Clin Infect Dis, 15 Suppl 1, S216-227.

Rustveld, L.O., Kelsey, S.F. \& Sharma, R. (2008) Association between maternal infections and preeclampsia: a systematic review of epidemiologic studies. Matern Child Health J, 12, 223-242.

Sahm, D.F., Thornsberry, C., Mayfield, D.C., Jones, M.E. \& Karlowsky, J.A. (2001) Multidrug-resistant urinary tract isolates of Escherichia coli: prevalence and patient demographics in the United States in 2000. Antimicrob Agents Chemother, 45, 1402-1406.

Sandberg, T., Kaijser, B., Lidin-Janson, G., Lincoln, K., Orskov, F., Orskov, I., Stokland, E. \& Svanborg-Eden, C. (1988) Virulence of Escherichia coli in relation to host factors in women with symptomatic urinary tract infection. J Clin Microbiol, 26, 1471-1476.

Sayres, W.G., Jr. (2010) Preterm labor. Am Fam Physician, 81, 477-484.

Santos, F., Oraichi, D., Bérard, A. (2010). Prevalence and predictors of anti-infective use during pregnancy. Pharmacoepidemiol Drug Saf, 19(4):418-427.

Santos, F., Sheehy, O., Perreault, S., Ferreira, E., Berard, A. (2010b). Exposure to antiinfective drugs during pregnancy and the risk of small-for-gestational-age newborns: a case-control study. Proceedings of the 26th International Conference on Pharmacoepidemiology and Therapeutic Risk Management, Pharmacoepidemiol Drug Saf, 19: S1-S347, Brighton, UK, Aug. 2010.

Schieve, L.A., Handler, A., Hershow, R., Persky, V. \& Davis, F. (1994) Urinary tract infection during pregnancy: its association with maternal morbidity and perinatal outcome. Am J Public Health, 84, 405-410.

Schmiemann, G., Kniehl, E., Gebhardt, K., Matejczyk, M.M. \& Hummers-Pradier, E. (2010) The diagnosis of urinary tract infection: a systematic review. Dtsch Arztebl Int, 107, 361-367. 
Schnarr, J. \& Smaill, F. (2008) Asymptomatic bacteriuria and symptomatic urinary tract infections in pregnancy. Eur J Clin Invest, 38 Suppl 2, 50-57.

Shand, D.G., Nimmon, C.C., O'Grady, F. \& Cattell, W.R. (1970) Relation between residual urine volume and response to treatment of urinary infection. Lancet, 760, 13051306.

Sharma, P. \& Thapa, L. (2007) Acute pyelonephritis in pregnancy: a retrospective study. Aust N Z J Obstet Gynaecol, 47, 313-315.

Sheffield, J.S. \& Cunningham, F.G. (2005) Urinary tract infection in women. Obstet Gynecol, 106, 1085-1092.

Simmons, L.E., Rubens, C.E., Darmstadt, G.L. \& Gravett, M.G. (2010) Preventing preterm birth and neonatal mortality: exploring the epidemiology, causes, and interventions. Semin Perinatol, 34, 408-415.

Smaill, F. (2000) Antibiotics for asymptomatic bacteriuria in pregnancy. Cochrane Database Syst Rev, CD000490.

Smaill, F. (2007) Asymptomatic bacteriuria in pregnancy. Best Pract Res Clin Obstet Gynaecol, 21, 439-450.

Smaill, F. \& Vazquez, J.C. (2007) Antibiotics for asymptomatic bacteriuria in pregnancy. Cochrane Database Syst Rev, CD000490.

Spinillo, A., Capuzzo, E., Stronati, M., Ometto, A., De Santolo, A. \& Acciano, S. (1998) Obstetric risk factors for periventricular leukomalacia among preterm infants. Br J Obstet Gynaecol, 105, 865-871.

Stamey, T.A., Fair, W.R., Timothy, M.M. \& Chung, H.K. (1968) Antibacterial nature of prostatic fluid. Nature, 218, 444-447.

Tugrul, S., Oral, O., Kumru, P., Kose, D., Alkan, A. \& Yildirim, G. (2005) Evaluation and importance of asymptomatic bacteriuria in pregnancy. Clin Exp Obstet Gynecol, 32, 237-240.

Turck, M., Goffe, B.S. \& Petersdorf, R.G. (1962) Bacteriuria of pregnancy. Relation to socioeconomic factors. N Engl J Med, 266, 857-860.

Turiani, M. (2009) Habitos de Higiene Genital e Infeccao autorreferida no trato urinario na gravidez Escola de Enfermagem. Universidade de Sao Paulo, Sao Paulo, pp. 94.

Vazquez, J.C. \& Villar, J. (2003) Treatments for symptomatic urinary tract infections during pregnancy. Cochrane Database Syst Rev, CD002256.

Verani, J.R., McGee, L. \& Schrag, S.J. (2010) Prevention of perinatal group B streptococcal disease--revised guidelines from CDC, 2010. MMWR Recomm Rep, 59, 1-36.

von Dadelszen, P. \& Magee, L.A. (2002) Could an infectious trigger explain the differential maternal response to the shared placental pathology of preeclampsia and normotensive intrauterine growth restriction? Acta Obstet Gynecol Scand, 81, 642648.

Wagenlehner, F.M., Weidner, W. \& Naber, K.G. (2009) An update on uncomplicated urinary tract infections in women. Curr Opin Urol, 19, 368-374.

Wax, J.R., Cartin, A. \& Pinette, M.G. (2010) Biophysical and biochemical screening for the risk of preterm labor. Clin Lab Med, 30, 693-707.

Whalley, P.J., Martin, F.G. \& Peters, P.C. (1965) Significance of Asymptomatic Bacteriuria Detected during Pregnancy. JAMA, 193, 879-881. 
Wing, D.A. (1998) Pyelonephritis. Clin Obstet Gynecol, 41, 515-526.

Wullt, B., Bergsten, G., Samuelsson, M. \& Svanborg, C. (2002) The role of P fimbriae for Escherichia coli establishment and mucosal inflammation in the human urinary tract. Int J Antimicrob Agents, 19, 522-538. 


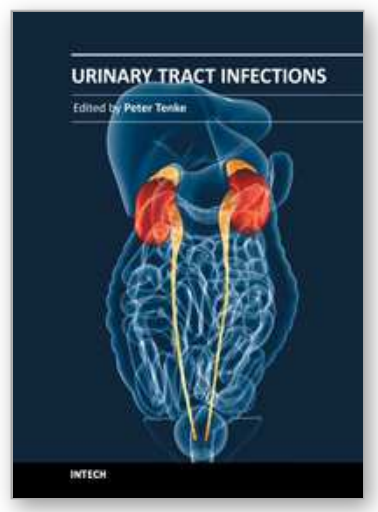

\author{
Urinary Tract Infections \\ Edited by Dr. Peter Tenke
}

ISBN 978-953-307-757-4

Hard cover, 360 pages

Publisher InTech

Published online 30, September, 2011

Published in print edition September, 2011

Urinary tract infections (UTIs) are among the most common bacterial infections worldwide, and they are also the leading cause of hospital-acquired infections. Therefore, the appropriate management of UTIs is a major medical and financial issue. This book covers different clinical manifestations of UTI, with special emphasis on some hard-to-treat diseases, and special conditions in respect of treatment; antibiotic resistance and the available alternative strategies for the prevention and treatment of UTIs and it deals with urinary tract infections in children. The aim of this book is to give a summary about the different aspects of the diagnosis, management and prevention of urinary tract infections for all medical disciplines.

\title{
How to reference
}

In order to correctly reference this scholarly work, feel free to copy and paste the following:

Anick Bérard, Fabiano Santos, Ema Ferreira and Sylvie Perreault (2011). Urinary Tract Infections During Pregnancy, Urinary Tract Infections, Dr. Peter Tenke (Ed.), ISBN: 978-953-307-757-4, InTech, Available from: http://www.intechopen.com/books/urinary-tract-infections/urinary-tract-infections-during-pregnancy

\section{INTECH}

open science | open minds

\section{InTech Europe}

University Campus STeP Ri

Slavka Krautzeka 83/A

51000 Rijeka, Croatia

Phone: +385 (51) 770447

Fax: +385 (51) 686166

www.intechopen.com

\section{InTech China}

Unit 405, Office Block, Hotel Equatorial Shanghai

No.65, Yan An Road (West), Shanghai, 200040, China

中国上海市延安西路65号上海国际贵都大饭店办公楼 405 单元

Phone: +86-21-62489820

Fax: +86-21-62489821 
(C) 2011 The Author(s). Licensee IntechOpen. This chapter is distributed under the terms of the Creative Commons Attribution-NonCommercialShareAlike-3.0 License, which permits use, distribution and reproduction for non-commercial purposes, provided the original is properly cited and derivative works building on this content are distributed under the same license. 